\section{GENERATION X-RAY - A COMING OF AGE}

\author{
Gavin Connor Fox \\ Synchrotron Soleil, Saint Aubin, Gif-sur-Yvette, France \\ gavin.c.fox@gmail.com
}

\section{GENERACIÓN RAYOS-X - MAYORÍA DE EDAD}

gavin.c.fox@gmail.com

Citation/Cómo citar este artículo: Fox, G.C. (2015).

"Generation X-ray - A Coming of Age". Arbor, 191 (772): a221. doi: http://dx.doi.org/10.3989/arbor.2015.772n2007

Received: September 12, 2014. Accepted: February 13, 2015.
Copyright: (C) 2015 CSIC. This is an open-access article distributed under the terms of the Creative Commons Attribution-Non Commercial (by-nc) Spain 3.0 License.
ABSTRACT: In 2014, the scientific community celebrated the impact crystallography has had on fundamental and applied science, and the ground-breaking discoveries that have gifted us with vision into the molecular and nano-worlds. UNESCO has declared 2015 as the International Year of Light, so now is perhaps a well timed moment to reflect on the role synchrotrons play in the field. Access to synchrotron radiation has revolutionized our ability to explore the properties, interactions and structure of materials, and broadened our understanding in diverse scientific arenas ranging from our cultural heritage, to nano-technology and new materials, to cellular systems and drug discovery. The range of potential synchrotron applications and fields of interest is enormous and beyond the scope of any single article, so my aim here, is simply to provide a snapshot filtered through the lens of biological crystallography. We will look back at how synchrotrons developed into the state-ofthe-art facilities we see today, how beamlines adapted to the quickening brought on by the introduction of high throughput techniques at the turn of the millennium, and forward to some of the new directions and technologies that are transforming modern light sources and crystallography.

KEYWORDS: beamline; light sources; membrane protein; microfluidics; protein crystallography; serial crystallography; structural biology; synchrotron; XFEL.
RESUMEN: La comunidad científica celebró en 2014 el impacto que la cristalografía ha tenido sobre la ciencia fundamental y aplicada, así como los de descubrimientos relevantes que nos han proporcionado una visión del mundo a escala molecular y nanométrica. La UNESCO ha declarado 2015 como el Año Internacional de la Luz por lo que quizás es un buen momento para reflexionar sobre el papel que han jugado y juegan los sincrotrones en esta ciencia. El acceso a la radiación sincrotrón ha revolucionado nuestra capacidad para explorar las propiedades, interacciones y estructura de materiales, así como ampliado nuestro conocimiento en distintos contextos científicos, desde el patrimonio cultural a la nanotecnología y nuevos materiales, hasta la exploración de sistemas celulares y búsqueda de fármacos. El rango de potenciales aplicaciones de los sincrotrones y sus campos de interés es vasto y queda fuera del alcance de un único artículo por lo que la intención del autor es la de proporcionar una imagen de los sincrotrones obtenida a través del filtro de la cristalografía macromolecular. Echaremos la vista atrás para ver cómo los sincrotrones han ido evolucionado hasta llegar a las actuales instalaciones en donde las líneas de trabajo asociadas a los mismos se están adaptado rápidamente a la introducción de las técnicas de alto rendimiento en el cambio del milenio; pero también miraremos hacia el futuro, hacia las nuevas tendencias y tecnologías que ya están transformando las actuales instalaciones y la misma cristalografía.

PALABRAS CLAVE: biología estructural, cristalografía de proteínas, cristalografía en serie, línea, fuentes de luz, microfluídica, proteínas de membrana, sincrotrón, XFEL. 


\section{AN INTRODUCTION TO MODERN LIGHT SOURCES}

Synchrotrons are a type of circular particle accelerator that generate very bright light in the region of the electromagnetic spectrum from infrared through to X-rays. Most synchrotrons operate 24 hours a day 7 days a week during cycles, to provide access and support for experiments carried out by thousands of scientists each year. To give some examples of scale, the most recent machines have a diameter about the size of a football field and produce $\mathrm{X}$-rays around a billion times brighter than a conventional X-ray machine in a hospital. More than 70 synchrotrons in various stages of development are in operation around the world. These large high-tech construction projects represent major investments in scientific infrastructure at the national level. So why do we need these huge installations? And what exactly do they do?

Synchrotrons are now established landmarks on the scientific landscape of many countries and are playing increasingly important roles in transnational research networks as integrated platforms. They are hubs that bring together scientists, engineers, technologists and industrialists who exploit the intensity and spectral properties of synchrotron radiation to characterize samples or processes. Often this requires cutting-edge technology and there is a direct synergy between experimental design and instrumentation development, which means that first and foremost synchrotrons act as science and technology drivers. Large national sources such as Soleil, generate hundreds of publications in scientific journals every year and pave the way for the development of new technologies and materials with applications in diverse sectors. The broad spectrum of scientific and technical knowledge produced is disseminated out to the wider community through collaborations, training networks and education programs, and as we shall see, can have major impacts on specific fields such as structural biology.

However, synchrotrons are more than just the sum of the knowledge they produce and have many less tangible benefits. To stay competitive, synchrotron facilities are constantly upgraded as technologies improve and research frontiers progress. This drives innovation, and clusters of small high-tech businesses or spin-off companies supplying technology, analytical expertise and services tend to gravitate around synchrotrons. Researchers from larger industries, particularly the pharmaceutical and micro-electronic sectors, rely on access to synchrotrons as the only tool powerful enough to analyse their samples at high spatial resolutions. Some synchrotrons also commer- cialize the technologies and software they develop for services geared towards industry and hospitals. This socio-economic activity and innovative dynamic propagates well beyond the gates of the synchrotron.

\section{THE ORIGINS OF SYNCHROTRON RADIATION}

Synchrotron radiation is as old as the stars and is one of the most pervasive radiative processes in the Universe. For example, the bluish-glow infusing the Crab Nebula is due to synchrotron radiation from charged particles spiraling around magnetic fieldlines thrown out by a rotating neutron star (Dean et al., 2008). Many other supernova remnants, pulsars, plasma jets, and our own Galaxy, also emit natural synchrotron radiation. But it wasn't until 70 years ago that, with a minor stroke of serendipity, man-made synchrotron radiation was first observed on earth.

\section{A Voyage of Discovery}

In the mid 1920s, physicists began to assemble magnetic-induction electron accelerators (Betatrons) to produce high energy X-rays for nuclear research. These machines based on cyclotrons used radio-frequency (RF) fields to accelerate particles in dough-nut shaped "electron tubes". On April 24, 1947, a technician working with Herb Pollock, Robert Langmuir, Frank Elder, and Anatole Gurewitsch at the General Electric Laboratory, Schenectady, New York, peered cautiously around the shielding of a newly assembled betatron to check for sparking (Figure 1). What he saw, was a brilliant arc of white light emanating from the transparent tube. Langmuir was first to recognize this as "Schwinger radiation" (Elder et al., 1947), and with a single intuitive leap and the following quote, which by theoretical physics standards radiates excitement, the age of synchrotron radiation had begun.

\footnotetext{
"The radiation from electrons in a betatron or synchrotron should be emitted in a narrow cone tangent to the electron orbit, and its spectrum should extend into the visible region. This radiation has now been observed visually in the General Electric 70-Mev synchrotron." (Elder, Langmuir and Pollock, 1948).
}

The theoretical basis of synchrotron light can be traced as far back as the late $19^{\text {th }}$ century to the work of Ludwig Lorenz and the discovery of the electron by J.J. Thomson in 1897. In the same year as Thomson's momentous discovery, the son of a Belfast shopkeeper - Joseph Larmor, published an expression from classical electrodynamics for the instantaneous total power radiated by an accelerated charged particle (Larmor, 1897). The following year, Alfred Liénard working at 
the École des Mines in Paris, extended this result to the case of a relativistic particle undergoing centripetal acceleration in a circular trajectory. Liénard's formula showed the radiated power of a charged particle to be proportional to the radius of the trajectory and described the concept of retarded potentials that is now known as synchrotron radiation (Liénard, 1898). Emil Wiechert independently came to the same conclusions and the theoretical framework under-pinning Liénard-Wiechert field potentials is still taught in modern physics texts today. Other theoreticians, notably Pomeranchuk in the Soviet Union and Julian Schwinger in the US (whose quantum electrodynamic model won the Nobel Prize with Richard Feynman and Sin-Itrio Tomonaga in 1965), elaborated and refined the classical theory of radiation from accelerated relativistic electrons (Schott, 1907; Iwanenko and Pomeranchuk, 1944; Blewett, 1946; Schwinger, 1949).

Figure 1. The team behind the first observation of man-made Synchrotron radiation at the GE laboratories: Left to Right: Robert Langmuir, Frank Elder, Anatole Gurewitsch, Ernest Charlton and Herb Pollock.

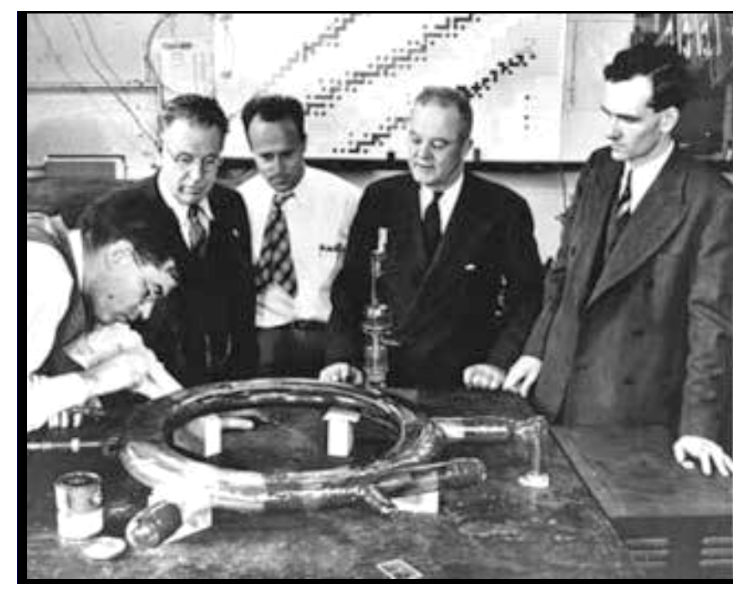

\section{The First Generation Sources}

During the 1950s, larger synchrotrons were built at the Lebedev Institute in Moscow and at Cornell in the US for high energy or nuclear physics. Although some demonstration experiments with synchrotron light were carried out on these sources, losses of energy due to synchrotron radiation were generally considered a nuisance and synchrotron experiments a parasitic form of operation. It was not until a synchrotron built by the US National Bureau of Standards (now NIST) was modified in 1961 to allow regular access to synchrotron light for spectroscopy experiments that the real potential began to reveal itself. The word spread fast, and the pioneering work at the Synchrotron Ultraviolet Radiation Facility (SURF) as it became known, was closely followed by the Frascatti Laboratory near Rome and the INS-SOR group at Tokyo, who began measuring the absorption spectra of metals. Demand began to grow for higher energy machines capable of producing shorter wavelengths and was met by the 6-GeV Deutsches Elektronen-Synchrotron (DESY) built in Hamburg in 1964. A year later, the first purpose built electron storage ring (Tantalus1) began operation at the University of Wisconsin, which with its stable operation mode and complement of beamlines, became a basic model for today's multi-faceted storage rings. The success of this model was soon replicated at the ACO storage ring at the Orsay Laboratory (France), which later developed into the SuperACO ring LURE then Soleil, and at DORIS in Germany, to name but a few early examples. The moniker "synchrotron" commonly used for the machines built after this date based on the Tantalus design, is not in fact the correct terminology, and they are more properly referred to as electron storage rings.

\section{Second Generation: The Storage Rings}

As the number of synchrotron applications grew, so did the clamor for fully dedicated sources. This burgeoning demand was addressed by the construction of a series of second generation sources in the early 1980s starting with the Synchrotron Radiation Source at Daresbury in the UK. Synchrotrons built around this time including the NSLS in Brookhaven (US), the KEK "Photon Factory", Tsukuba, Japan and BESSY in Berlin, forged the mold for modern light sources and became highly productive facilities. They expanded the range of techniques available to include beamlines dedicated to protein crystallography and pioneered many of the methods still in use today. The spectral range also widened progressively to span from infrared to hard X-rays.

One of the key trends that emerged at this time was a need for increased spectral brightness or "brilliance". Unfortunately, over the years several terms have been used interchangeably for this concept, but the correct meaning can be inferred from the units which are photons $/ \mathrm{s} / \mathrm{mm}^{2} / \mathrm{mrad}^{2} / 0.1 \%$ band-width. Hence, brilliance takes into account the density of photons over a given area and time, as well as the angular divergence of these photons (or how fast they spread out), and the fraction that fall within a specified wavelength or photon energy range. The greater the brilliance, the more photons of a given energy can be concentrated on a single spot. This is one of the key parameters that allow us to compare different light sources. The quest for 
greater brilliance marked the progression of synchrotron science into the modern era and is one of the main drivers in the design of new light sources.

\section{Third Generation: High Brilliance Sources}

The pursuit of this goal led to the construction of a new generation of synchrotron sources optimised for high brilliance. As we shall see, synchrotron rings are constructed from "bending magnets" that keep the electron beam in a circular orbit. One means to boost the brilliance of radiation produced in a storage ring is to introduce periodic magnetic arrays known as insertion devices, which locally perturb the electron beam. The third generation synchrotrons built in the 1990s, such as the APS (Argonne, US), SPring-8 (Japan), and the ESRF (Grenoble, France), were much larger machines designed with extended "straight sections" between bending magnets to accommodate insertion devices. These machines were orders of magnitude more powerful than second generation sources and were specified to operate at higher energies, opening up access to harder X-rays. They were also designed as major user facilities with on-site hotels and upwards of 40 independent experimental stations (beamlines), capable of hosting hundreds of scientists at a time. The ESRF was co-financed by a consortium of EU counties, and along with CERN, stands out as a shining example of European scientific cooperation. Similar transna- tional partnership models have now been adopted for the fusion project ITER in the south of France, and the European Free Electron Laser (XFEL) currently under construction in Hamburg.

The spectacular success of these sources and continued growth in the synchrotron user community (the number of users at the four major US synchrotron facilities rose from 6,009 to 8,492 between 2000 and 2008) led to the construction or refurbishment of a series of national light sources. These sources include the Swiss Light Source (2000), the Canadian Light Source (2004), Soleil (France) and the Australian Synchrotron in 2006, Diamond (UK) and Indus-II (India) in 2007, the Shanghai Synchrotron Radiation Facility in 2008, Petra-III (Germany) in 2009, and ALBA (Spain) in 2010 (Figure 2). With the exception of PetraIII, which is a high energy machine operating at $6 \mathrm{GeV}$ to provide harder X-rays, most of the national sources are relatively compact rings specified in the medium energy range between 2.4 and $3 \mathrm{GeV}$. Synchrotrons currently being commissioned or under construction include the NSLS-II (US), Max IV (Sweden), SESAME (Jordan), TPS (Taiwan), SOLARIS (Poland), along with several new projects planned for Armenia, Brazil and China. These machines have emittance ${ }^{\S}$ (4 nm.rad or less) and brilliance characteristics $\left(10^{20} \mathrm{ph} / \mathrm{s} / 0.1 \%\right.$ band-width $/ \mathrm{mm}^{2} / \mathrm{mrad}^{2 *}$ ) that are comparable to, or better than, the original third generation sources.

Figure 2. Examples of recent $3^{\text {rd }}$ Generation storage-rings: Left: ALBA (Barcelona). Right: SOLEIL (Paris)

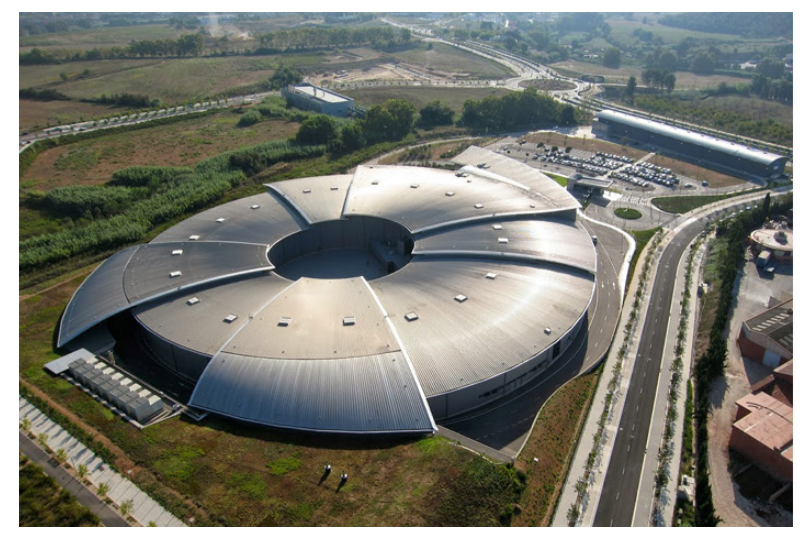

\section{THE NATURE OF SYNCHROTRON RADIATION}

Let us turn to the properties of synchrotron light and how it is produced in a little more detail. In classical physics, the emission of electromagnetic waves - including X-rays - requires the acceleration of an electric charge. This basic concept does not alter radically at the quantum level (Bosco, Colson and Freeman,1983; Dattoli et al., 1985), and put simply, any

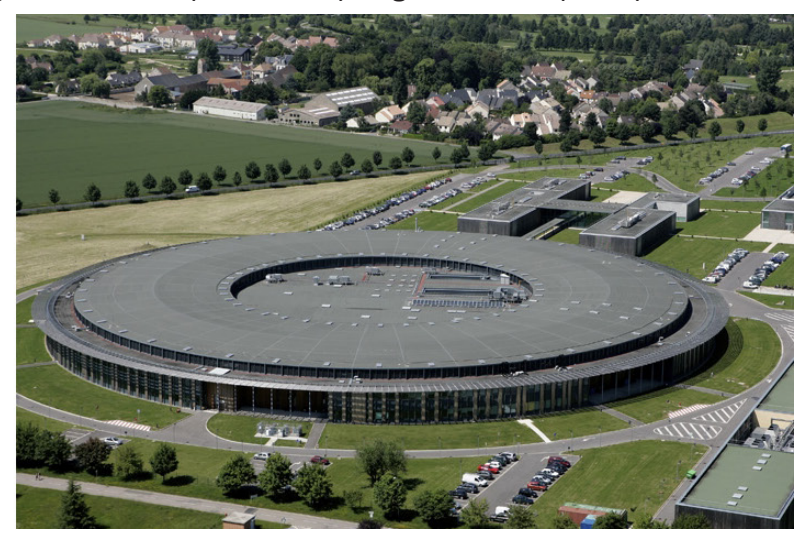

unbound charged particle accelerating close to the speed of light emits energy (as radiated photons) when forced to deviate from a linear path. Synchrotrons are designed to exploit relativistic effects to generate radiation with good properties to explore matter in two ways. Firstly, the energy of the accelerated particle determines the frequency of emitted radiation, and for particles traveling close to the speed of light the frequency observed from the beamline frame of 
reference, is shifted to higher frequencies due to the Doppler effect. This is a similar phenomenon to the change in pitch of a train horn as a train moves towards the observer. The Doppler shift is characterized by the Lorentz factor $\gamma$, which is defined as the rest mass energy of the electron divided by its total energy (Brau, 2004). Relativistic length contraction also boosts the frequency of emitted radiation by another factor of $\gamma$, amplifying the frequency into the $\mathrm{GHz}$ or $\mathrm{X}$ ray range. Secondly, close to the speed of light, the energy emitted is beamed into a narrow forward-pointing cone. This radiation has a small natural emission cone, which is referred to as the opening angle given by $\gamma^{-1}$. Combined, these two factors give synchrotron light its remarkable brightness and collimation.

Another useful property caused by the planar acceleration geometry, is that the radiation appears linearly polarized when observed in the orbital plane and circularly polarized when observed at a small angle to that plane. The characteristics of synchrotron light; broad emission spectrum, high brilliance, collimation, polarisation and pulsed time structure (caused by the separation of distinct electron bunches circulating in the ring), make it an immensely powerful tool for studying the atomic structure of matter of all kinds.

\section{PRODUCTION OF SYNCHROTRON LIGHT}

\section{The Accelerator Complex}

Although they vary in size and energy, third generation sources have similar design concepts. The first requirement in generating light with very short wavelengths is an accelerator producing high energy electrons. Typically, the electrons are accelerated in stages in a complex that includes a linear accelerator (Linac) and an intermediate Booster ring. The Linac contains a large electron gun that produces a pulsed train of electrons separated into bunches. In the gun, free electrons are generated by a high voltage heating element in a negatively charged metal block, then "chopped" into shorter bunches and propelled through an electric field. At the exit, the pulse length is further shortened by a "grouper" or pre-buncher, and the electrons are accelerated to close to the speed of light by one or more linear accelerators. The energy required for this acceleration is supplied by powerful microwave amplifiers known as klystrons. The frequency of bunches emitted by the grouper is matched to the in-coming radiation from the klystrons so that the electrons always resonate in phase to progressively ramp their energy as they pass through the Linac. At the end of the Linac, the electrons are channeled into the Booster synchrotron by a transfer line that adjusts the average energy of the bunches to coincide with the desired beam characteristics of the Booster.

The Booster is a relatively small synchrotron ring, and as the name suggests, acts to further accelerate and refine the dimensions and energy dispersion of the bunches. When electrons enter into the Booster they are accelerated within a couple of hundred milliseconds to energies in the Giga-electronvolt range. This rapid acceleration is achieved by pumping radiofrequency (RF) energy into the electrons as they pass through resonating RF cavities during each cycle. The RF system tunes the distance between electron bunches, and by varying this parameter, different bunch distributions or "fill" patterns can be selected for operation modes with specific time structures. The electrons circulate several hundred thousand times before attaining the normal working energy of the synchrotron, and are then injected into the storage ring. Typically, dozens of Linac-Booster injection cycles are needed to accumulate enough bunches to fill a storage ring. The final number of bunches circulating in the main ring is characterized by a current (usually several hundred $\mathrm{mA}$ ), which is another machine characteristic that describes the intensity of the source.

\section{The Storage Ring}

The idea of using storage rings as a means to achieve higher flux from linear accelerators was first proposed by Gerard O'Neill in 1956 (O'Neill, 1956). The concept is relatively simple and involves the arrangement of magnetic fields in a geometry that will deflect a particle beam into a closed circular path (Figure 3). However, major technological hurdles had to be overcome to achieve the stability and performance of today's machines. The early ring designers realized that the most practical way to guide the trajectory of an electron beam into a circular orbit was by using dipole "bending" magnets to deflect a beam in consecutive arcs. From Liénard we know that for electrons forced to travel in a circle, the net energy lost as synchrotron radiation is inversely proportional to the square of the radius of their path. This comes into play when deciding the diameter of storage rings and is the reason that synchrotrons operating at the currently maximum obtainable energies, such as the Large Electron-Positron Collider (LEP) at CERN, have very large diameters ( $8 \mathrm{~km}$ in the LEP case). The radiation emitted by larger rings ranges from infrared to gamma rays, but third generation sources are specified so that peak emissions are centered on the X-ray range as these wavelengths are comparable with inter-atomic distances. 
Besides the difficulty of building large rings, it was clear even before O'Neill first promoted the storage ring concept that dipoles alone would only produce "weak focusing" sources of low brilliance due to Coulomb forces which act to spread out the beam as it is deflected by each magnet. The solution to this problem is to interpose the dipoles with quadrupole and sextupole magnets to compress or refocus the beam as it is curved. Sextupoles also play important roles in steering the beam and correcting for chromaticity in the bunches, which arises because dipole and quadrupole magnets deflect particles with energies slightly outside the norm by differing amounts. Storage rings are constructed from dozens of these elements arranged in a symmetrical magnetic lattice that can focus a beam circulating for hours to less than the breadth of a hair. Over the years several lattice configurations have been tried and tested, but the most commonly used arrangement in current sources is the double-bend achromat lattice designed in the 1970s by Renate Chasman and George Green (Chasman and Green, 1975). The success of this lay-out comes down to the very low emittance that can be achieved for beams maintained in this pattern. The lattice configurations of recent sources, combine highly optimised ratios of available straight sections for insertion devices, with exquisite control over the trajectory, shape and stability of the beam.

The principle role of any storage ring is of course to maintain a stable beam for extended periods. Because energy is continually radiated, storage rings also contain RF cavities that restore the energy of passing electrons. Nonetheless, a significant percentage of electrons will be lost in the hours following their injection into the ring. This "life-time" and the stability of the beam current can be critical issues for experiments lasting several days. At Soleil, which is one of the most stable light sources available, the current can drop by up to $30 \%$ eight hours after a refill. To overcome this, recent sources operate in "Top-up" modes. This means that the beam current is kept steady by regular small injections at short periodic intervals. Another more prosaic, but no less important factor in keeping the current stable, is that particles circulating in a ring many millions of times would have very short life-times due to collisions with residual gas particles, unless an ultra-high vacuum can be preserved. Most storage rings operate under a vacuum of the order of $10^{-9} \mathrm{~Pa}$, which is only an order of magnitude less than the vacuum on the surface of the moon at night (LADEE Mission. NASA, 2013).

\section{Insertion Devices}

As previously mentioned, third generation sources produce much more intense radiation by incorporating insertion devices between the bending magnets of the storage ring. These are linear arrays of magnets stacked side-by-side with alternating polarities to create a periodic magnetic field. When electrons pass through such fields they are forced to oscillate in a sinusoid or helical path. At each change of direction photons are emitted in a narrow cone, and the periodicity of the field-flipping is calculated precisely so that the cones over-lap to amplify the radiation produced. Insertion devices are designed to induce a great number of oscillations or "wiggles" without perturbing the beam trajectory, and produce photon beams up to 10 thousand times more brilliant than bending magnets. Insertion devices fall into two main categories, wigglers and undulators (Figure 3). Wigglers generate radiation in a continuous emission spectrum, with more intensity at higher energies. Undulators are designed so that the electron beam oscillates with a smaller amplitude, giving emission spectra with peaks at certain energies due to interference as the cones superimpose. These spectral peaks, or harmonics, are several orders of magnitude more intense than wiggler radiation. The distance between opposing magnets in an undulator are optimised for each experiment so that the beam intensity is maximised at any energy selected within the accessible range. Until the mid 1990s undulators were still relatively exotic, but they are now a mature well characterised technology, and are by a long way the most widely used source for beamlines.

The radiation emitted from storage rings is transported under ultra-high vacuum to beamlines laid out at tangents to the circumference of the ring. Beamlines come in many shapes and sizes and each beamline specializes in a particular set of techniques or applications. One of the most narrowly specialized group of beamlines in terms of techniques, are beamlines dedicated to bio-crystallography (PX).

\section{PX BEAMLINES}

PX beamlines may be tightly focused on a single technique - measuring X-ray diffraction from crystals of proteins, nucleic acids and viruses; but they do it extremely well and are among the most productive beamlines around. The massive growth in this field since the start of the genomic era translated directly into a surge in the number of synchrotron users, so much so, that for most light sources the number of visits to PX beamlines 
Figure 3. Left: Storage Ring schematic. Right Top: Schematic representation of an undulator (source: www.esrf. eu). Right Bottom: HU252 APPLE II type undulator during testing at Soleil.
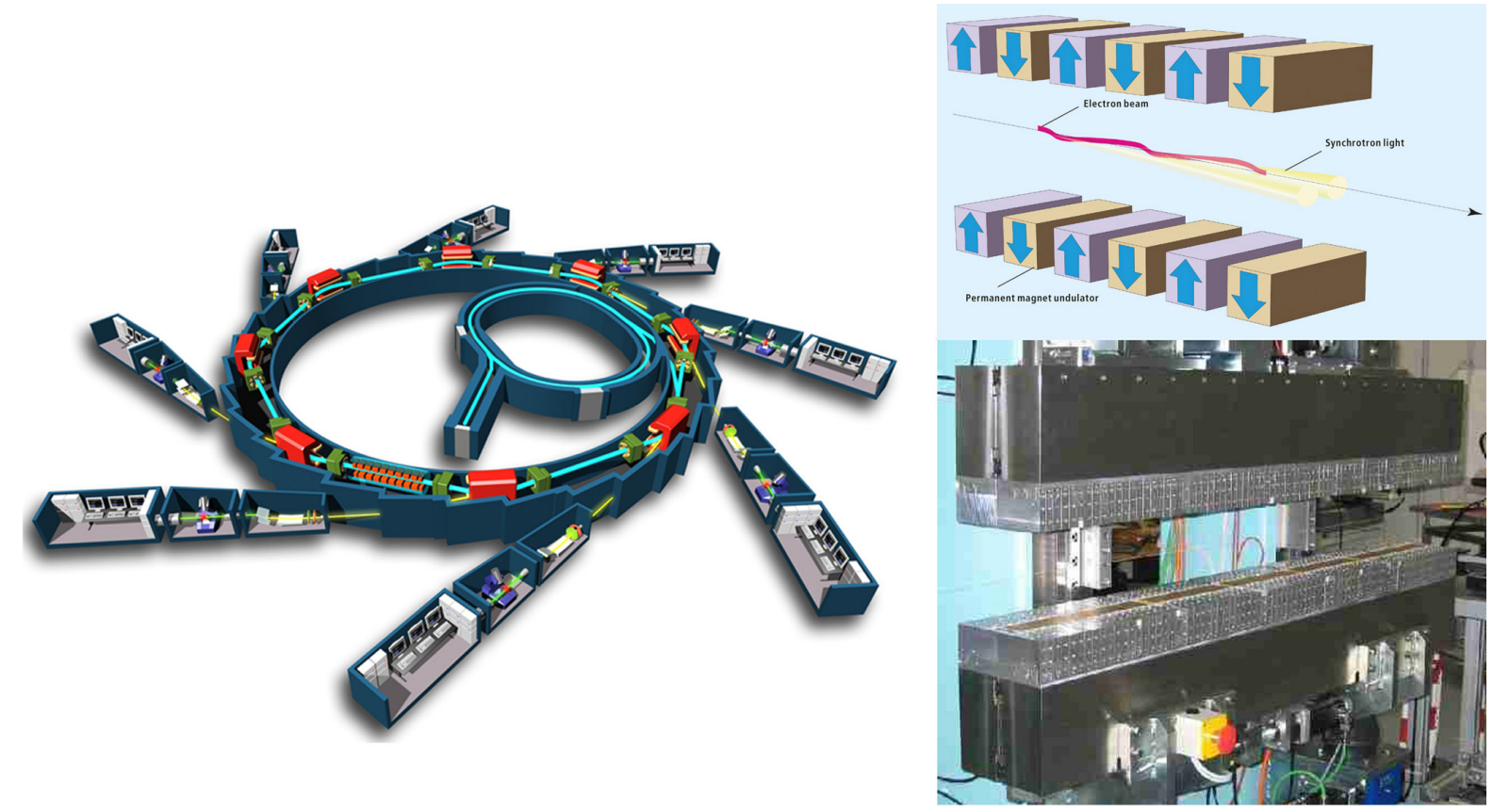

now represents a large fraction of the total number of user visits per year. This expansionary period ushered in major changes in the way PX beamlines function and mdern beamlines are extremely efficient, stream-lined operations with a level of technical sophistication that far surpasses what was conceivable at the turn of the millennium.

Beamlines reflect the community they are built to serve, and the advances we see today are a product of the rapid changes in structural biology in recent years. The remarkable gains in efficiency brought about by the introduction of high throughput techniques, from cloning and recombinant protein production to highly automated crystallisation platforms has meant that complex biological systems and entire cellular machines are now considered tractable targets for crystallography. Collecting data at synchrotrons is just a single cog in this wheel, but in many ways beamlines are the motor that drives the process forward. In this context, it is worth considering the trends influencing beamline development, and how these evolved in response to the changes in the field.

\section{The Basic Experiment}

To begin, let's consider the common elements of PX beamlines and the basic experiment they are set-up to tackle. The experiment itself is relatively simple and is based on the Rotation Technique popularized by UIrich Arndt and Alan Wonacott in the 1970s (Arndt and Wonacott, 1977). A crystal mounted on a magnetic pin is rotated in a monochromatic beam while an Xray sensitive camera records the patterns produced by scattered X-rays. Usually, the samples are maintained at cryogenic temperatures during transport to the synchrotron and throughout the data collection to protect them from dehydration and radiation damage. The strategies used to ensure that all unique positions in each crystal habit are measured with the highest accuracy possible are consistently the same, and have been elegantly reviewed by Zbigniew Dauter (Dauter, $1999,2005)$ and many other notable crystallographers (Chavas et al., 2012; Fodje et al., 2012; Krojer, Pike and von Delft, 2013). The final goal of the experiment is to combine measurements of the intensity of diffracted $X$-rays with information on their phases to calculate a map of the average electron density in the sample.

Direct phase information is lost during diffraction experiments, but can be recovered in a variety of ways; either using a set of phases borrowed from a structure similar enough to act as a molecular search template, or by using anomalous dispersion techniques (Hendrickson and Ogata, 1997; Dauter, Dauter and Dobson, 2002). In the latter, the wavelength of the beam is set precisely to maximise the anomalous scattering from atoms bound to the sample which are 
heavier than the Carbon, Oxygen, Hydrogen and Sulphur atoms that make-up proteins. Beamlines with fixed energies are not optimised for anomalous-phasing, but the nature of the basic diffraction experiment does not change greatly from one set-up to another. For this reason it is not surprising that PX beamlines have many common elements. The core elements are; a device for selecting a single wavelength or monochromatizing the beam, an optical system to focus the beam into a small intense spot, a goniometer to rotate the sample, and an X-ray sensitive detector. Of course, a huge amount of design optimisation and some very high-tech kit is added, but the core elements remain similar from site to site.

\section{Developmental Trends: Faster ... Smaller ... Brighter ...Better}

However technology never stands still, and in Europe alone 14 new PX beamlines have been built in the last 5 years. These beamlines were shaped by the experience gained from the earlier third generation sources, and by the currents that have swept through the community. Although each facility has its strengths, and for each new beamline built there is an impetus to push the technical boundaries, the basic design is guided mainly by consideration of the operating energy or range, the sample throughput, and the size and intensity of the focal spot.

Biological crystals are inherently complex and often display pronounced variability so many samples and different conditions have to be tested before a crystal with sufficient order to generate a high resolution electron density map is identified. The extent of this "screening" campaign usually correlates with the size and complexity of the structure being analysed. Automation has expedited the process and multiplied the number of conditions and samples being screened. Hence, modern PX beamlines are designed with turn-over in mind and will routinely process well over a hundred samples per day. Installations such as the MASSIF (Massively Automated Sample Selection Integrated Facility) suite at the ESRF have taken this principle to new levels of efficiency, and will be able to handle thousands of samples per day (Theveneau et al., 2013). The surge in through-put changed the way PX beamlines operate and the technology that is deployed. Beamline processes have to be extremely robust, and there is a premium on keeping the X-ray beam and instrumental configuration stable. This of course, influences the choice of technology and many beamlines now integrate industrial components such as high speed rotation stages and multi-axis robotic arms, more commonly found on production lines. Robotic sample-changers, which transfer samples from cryogenic storage tanks to the goniometer where they remain frozen by a stream of nitrogen gas at, $100 \mathrm{~K}$, have become common place. Coordination of sample exchange is often integrated into the data collection process and has been automated to an extent that at many sites, the experiment can be remotely controlled from the users' home institute (remote access). The extreme stability demanded for ultra-high throughput means that fixed energy beamlines are generally better adapted for this; however most of the beamlines built at national sources are tunable over an energy range that traverses the absorption edges of metals used for anomalous-phasing. This equates to around $6 \mathrm{KeV}$ to $18 \mathrm{KeV}$ and is well matched to the source characteristics of the medium energy storage rings constructed since the start of the century.

Another major developmental trend has been towards the production of ever smaller beams. Again, this is a direct consequence of the spread of automation in the post-genomic era. Recombinant techniques produce microgram quantities of purified protein at a time, so crystallisation experiments involve hundreds of automated trials using fractions of a microliter of sample. Frequently, micron-sized crystals are obtained by this route and a beam of similar size is needed to measure diffraction data with sufficient signal-to-noise ratios. PX beamlines have adapted, and the average focal spot size is now around 5 times smaller than 15 years ago. Many third generation sources have inaugurated beamlines specifically dedicated to microcrystallography. The latest crop of these beamlines, at Diamond, Petra-III and Soleil, incorporate optics capable of focusing to 5 microns or less. This is easier said than done. The refractive index of X-rays is close to 1 so they cannot be focused using traditional lenses. Instead mirrors set at low grazing incidence angles to the source are used to deflect and shape the beam. To avoid the reflected photons from spreading out and increasing the focal spot size as they travel away from the mirror, the surface has to be polished to extraordinary levels of perfection. After many years of development and craftsmanship in this field, "super-polishing" has matured to an extent that mirrors with an average roughness of less than a nanometer, or around 8 hydrogen atoms stacked on top of each other, can be manufactured (Sawhney, et al., 2013). At this degree of precision, tight control over vibrational and thermal stability must be built in to the design concept of the beamline. Proxima 2-A at Soleil uses adaptive bimorph mirrors (Khounsary et al., 1999) similar to the 
technology used to correct the sphericity of the largest optical telescopes, to perfect the shape of the surface and improve focusing. Refractive lenses that can efficiently focus $X$-rays and avoid the technical issues encountered with focusing mirrors are now also being integrated into the optical scheme of PX beamlines. This confluence of cutting-edge optical technology and recent developments in nano-metric positioning instrumentation, allow experiments to be conducted on crystals down to a few microns in size.

In sync with the wider trend toward increasingly brilliant sources, the fact that the most challenging structural targets produce small poorly ordered crystals has driven demand for PX beamlines to deliver more flux to the sample. Many of the most biologicalIy interesting systems have built-in flexibility or labile elements connected to their function, which limit the formation of stable lattice interactions within the crystal. Membrane proteins are a perfect example of this, and the technical challenge involved in crystallizing and determining their structure is apparent in the fact that less than $1.5 \%$ of the 101112 structures deposited in the PDB (as of 25 June 2014) are of membrane proteins (Membrane Proteins of Known 3DStructure. http://blanco.biomol.uci.edu/mpstruc). For membrane protein crystals, high flux densities are needed to extract diffraction signals at the highest possible spatial resolutions. The most powerful beamlines currently available can expose a crystal with 1 to 10 billion (10 $12-13$ ) photons per second. At Proxima 2-A, this is condensed into an area less than the size of a single red blood cell.

The other side of the signal-to-noise coin is the sensitivity of the detection system used to record the diffracted X-rays. Detector technology has progressed apace from re-usable photographic imaging plates and multi-wire gas-filled detectors in the early 1990s, to charge-coupled device (CCD) and pixel array detectors (PAD). Since 2007, large, extremely fast PAD detectors have been introduced on to PX beamlines. PAD detectors have zero electronic read-out noise and can be made sensitive enough to record each scattered photon that reaches the detector surface (Broennimann et al., 2006). Currently, the largest PADs are 425 by $435 \mathrm{~mm}^{2}$ and can read-out 6 million pixels in less than a millisecond. These detectors can operate at speeds of 100 frames per second or more, and are so fast that they have changed the way PX data is collected. In the classical rotation method, individual exposures are taken as a sample is rotated over small discrete steps, with a shutter closed while the detector reads-out.
The read-out times of PAD detectors are short enough that the sample can be continuously rotated to collect data without the need for an exposure shutter. This has a dramatic impact on the speed of the experiment and standard data sets are now collected in minutes, at least 10 times faster than with CCD detectors. Shutter-free modes and increased sensitivity also make fine-slicing strategies practical. Here, the quality and accuracy of data collected is optimised by fine-slicing through the diffraction sphere in thinner slices (Mueller, Wang and Schulze-Briese, 2012).

The uptake of PAD technology has brought about a burst in productivity, both in terms of the number of structures solved and the potential to collect accurate data from difficult crystals, but it has also opened up new experimental possibilities. Several beamlines have demonstrated the feasibility of using PADs to rapidly collect data at room temperature and in situ, that is without removing them from the media or crystallisation plate in which they are grown (Rajendran, et al., 2011; Owen et al., 2014). Other approaches made feasible include serial crystallography were many micro-crystals mounted on the same support are rapidly scanned to generate wedges of data that can be scaled together to reconstruct complete data sets (Gati et al., 2014; Stellato et al., 2014). These new approaches have the potential to create a paradigm shift in synchrotron crystallography.

\section{NEW DIRECTIONS}

\section{Integrated Pipe-lines and Sample Characterisation}

So this is an exciting time to be around synchrotrons - structural biology has matured into a mainstream technique and beamline developments are continuing apace. Many sites are beginning to offer flexible operation modes for PX experiments as remote access becomes more common. Full automation and sample information management systems such as ISPyB (Delagenière et al., 2011), allow the beam time allocated to individual groups to be broken down into shorter, more frequent sessions. Sites proposing high throughput screening will operate queuing systems with experimental slots assigned after the samples have been screened and ranked (Theveneau et al., 2013). Control over the screening and main data collection parameters will move online and be managed as web-services which should eventually be accessible as Apps. The local software pipe-lines to automatically process data, including GrenADES (Monaco et al., 2013), XIA2 (Winter, 2010), HKL-3000 (Minor et al., 2006) and XDSme 
(https://code.google.com/p/xdsme/), are getting smarter, and becoming fully integrated into the experimental work-flow as data collection queues and more advanced data collection strategies are implemented. Software for diagnosing crystalline pathologies (Zwart, Grosse-Kuntsleve and Adams, 2005) and calculating strategies taking into account radiation damage (Incardona et al., 2009; Bourenkova and Popov, 2010; Zeldin et al., 2013) are in use at many sites. Co-coordinated efforts to make these pipe-lines robust and capable of handling sophisticated work-flows are underway. At sites using ISPyB or other information management systems the results of automated data processing are accessible in real-time and updated live on-line. The main caveat in the push towards fully automated pipe-lines, is that synchrotron data collection will in many cases continue to be a non-trivial experiment, particularly when using micro-beams or phasing from weak anomalous signals. In the absence of a well thoughtthrough experimental plan and good choices made at the right time by an experienced user, potential pit falls remain (Soltis et al., 2008; Chavas et al., 2012; Fodje et al., 2012; Krojer, Pike and von Delft, 2013), and a time when the process can be treated as "hands-off" is still some way in the future.

However, the days when PX experiments entailed a simple rotation around a single axis are in the past, and the introduction of PAD detectors has made smarter characterisation and collection methods possible. Helical scans - were the crystal is translated linearly as it rotates in the beam, are available on many beamlines. Low dose line and grid-scanning to locate and centre barely visible crystals by their diffraction signal, are becoming more common particularly for membrane protein experiments. Of the 484 unique membrane protein structures solved by X-ray methods to date (Membrane Proteins of Known 3D Structure). (http://blanco.biomol.uci.edu/mpstruc) 47 were obtained from crystals grown in artificial lipid bilayers (The Cherezov Lab: Structures from LCP (http://cherezov.scripps.edu/structures.htm) using the in meso method first described by Landau and Rosenbusch (Landau and Rosenbusch, 1996; Pebay-Peyroula et al., 1997). Crystals grown this way are small, fragile and difficult to visualize in the media which becomes opaque when manipulated and cryo-cooled. Consequently, high speed raster-scanning to locate crystals grown in meso phases (Aishima et al., 2009; Cherezov et al., 2009; Evans et al., 2011) is becoming a standard tool. Alternative approaches for imaging crystals by X-ray microradiography and microtomography are also being trialled (Warren et al., 2013). Diffraction cartography, were the best diffracting zones in individual samples are micro-mapped (Bowler et al., 2010), is now routinely used for difficult cases such as membrane protein crystals, which are often nonhomogenous and prone to disorder.

\section{In Situ Diffraction and Microfluidics}

Another technique rapidly gaining ground is in situ diffraction screening. The crystallisation process for larger complexes is usually onerous and can require exhaustive trails that generate many non-optimised "hits". In situ screening is thus valuable in the early-stage characterization of possible conditions by providing rapid feed-back on the most promising candidates to follow up. No manual manipulation is involved, so the intrinsic diffraction properties of each sample can be assessed without the risks associated with crystal handling and freezing. Technical challenges arise when conducting in situ data collections, not least of which is managing the radiation damage to sensitive biological samples, but the advantages are clear and growing numbers of sites now support this type of experiment. The FIP beamline at the ESRF was the first to offer access to automated in situ modes and to integrate 6 -axis robotic arms that are now widely used for plate-screening at many synchrotrons (Jacquamet et al., 2004). Later, X06DA at the Swiss Light Source was expressly conceived as an automated in situ screening facility with an integrated crystallisation platform (Bingel-Erlenmeyer et al., 2011). 124 at Diamond has since laid much of the ground-work for in situ diffraction using micro-beams and has firmly established this technique for membrane protein crystallography (Axford et al., 2012). Beamlines at many other sites are now developing in situ capabilities using goniometers adapted for plates or commercial robotic arms.

One emerging application which shows much promise is the in situ analysis of crystals grown in microfluidic systems (Figure 4). A range of different chips exploiting alternative crystallisation mechanisms such as free interface diffusion [Topaz ${ }^{\mathrm{TM}}$, Fluidigm], liquid-liquid diffusion [Crystal Former ${ }^{\mathrm{TM}}$, Microlytic] or nano-batch methods $\left[\mathrm{MPCS}^{\mathrm{TM}}\right.$ system, Protein BioSolutions] have been commercialized. These techniques are complementary to the vapour diffusion crystallisation methods used in high throughput platforms, and allow different zones of the phase diagram to be finely sampled by gradients. The chips are manufactured from plastics that give low $X$-ray backgrounds, and can in some cases be used for de novo screening (Degen et al., 2014; Khatter et al., 
Figure 4. Left: The experimental cabin of Proxima2-A. Right: In situ screening of microfluidic chips. Inset - zoom of crystal grown by counter diffusion in a ChipX prototype. The $5 \times 10$ micron beam is represented by a blue box.
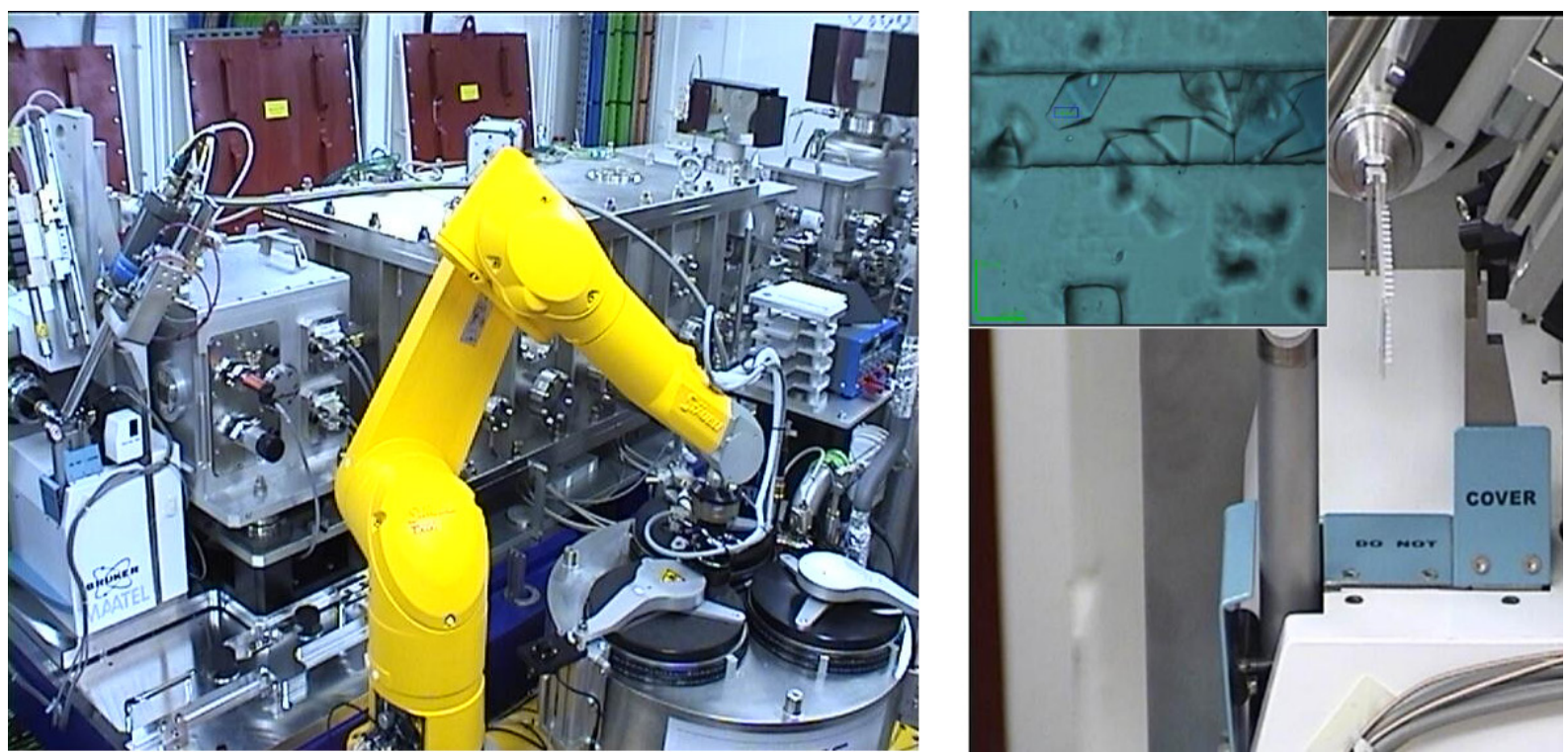

2014; Lee et al., 2014; Trastoy et al., 2014), but are more widely used for optimising hits discovered by traditional sparse-matrix screening. Droplet-based systems, such as the MPCS, are able to achieve very high throughputs with up to 800 gradient conditions per chip requiring just 5 microlitres of protein [pers com $-C$. Gerdts]. The currently available commercial chips are still relatively simple but more advanced designs and applications are beginning to come through. Chips optimised for parallelized counter diffusion experiments (Dhouib et al., 2009) and in meso batch experiments (Perry et al., 2009) have been reported. Another novel, potentially powerful in situ format is the Crystal Direct technology developed at the EMBL out-station in Grenoble (Cipriani et al., 2012). In this system, crystals grown on thin films are excised by laser ablation and automatically mounted on a magnetic pin. Automatic crystal harvesting has until now, been a bottle-neck in the automation chain. The Crystal Direct approach has the potential to create fully integrated pipe-lines from bench to beamline.

\section{Free Electron Lasers}

Despite the rapid pace of developments on synchrotron beamlines, the most demanding experiments being proposed today require a level of brilliance and time structures beyond the capabilities of third generation sources. Chemical and biological processes are dynamic, and are for the most part too fast to be resolved at synchrotrons which operate at frequen- cies of tens of picoseconds. A new generation of light sources with "shutter-times" fast enough to move beyond "static" averaged structures into time domains where molecular motion and reaction pathways can be resolved, is already with us.

Fourth generation sources, defined as those exceeding the performance of previous sources by at least an order of magnitude in terms of brilliance, coherence, or pulse duration, have been around in the guise of free electron lasers (FEL) for sometime. Low gain optical oscillator-mode FEL grew out of the microwave tube technologies developed during World War II to power radar systems, and FEL based light sources operating in the infra-red to UV range have been available since the 1990s. The idea of combining accelerator and laser physics to build X-ray FEL sources was first put forward by John Madey in 1971 (Madey, 1971; Elias et al., 1976). Laser light is generated by an amplification process called stimulated emission. This arises when electrons interacting with a particular frequency of radiation, drop to lower energy levels and transfer their energy as photons into a beam of light. The photons propagate in phase and the light produced is characteristically coherent. X-ray FEL use long undulators to generate pulses of radiation from "free" electrons. The transversal acceleration induced in undulators produces incoherent "spontaneous" radiation from randomly distributed electrons. In storage rings, there is no correlation in the position of 
electrons at the scale of the radiation wavelength so the cones of emitted radiation superimpose at random. However, in an X-ray FEL, the electron energies are modulated by the co-propagating electromagnetic field to give periodically spaced bunches with spacings equal to the radiation wavelength. This generates in-phase photons that superimpose to progressively ramp up the intensity of the light emitted.

As this intensity builds, electrons within a single wavelength tend to cluster closer together into micro-bunches. This phenomenon creates a positive feedback loop, due to the fact that as the interaction between the electrons and the electromagnetic field becomes stronger, the mechanism bringing them together becomes more powerful. This process, which is in fact a form of stimulated emission, can be either "seeded" by an external laser or self-amplified (SASE) within an undulator, and increases exponentially until it saturates at the point where all electrons are micro-bunched in phase (Bonifacio, Pellegrini and Narducci, 1984; Murphy and Pellegrini, 1985; Kim, 1986; Pellegrini, 1988). The bunch-trains are comprised of billions of electrons and as the intensity gain is proportional to the number of electrons squared, pulses of light many orders of magnitude brighter than synchrotrons are emitted. The wavelength of radiation can also be readily tuned by adjusting the energy of the beam or the magnetic field of the undulator.

FEL sources have been built using both storage rings (TERAS, UVSOR, VEPP-3, Super ACO) and Linacs as drivers. The latest FEL facilities are fed by high-energy Linacs one to two $\mathrm{km}$ in length. Facilities operating on the SASE principle include the Free electron LASer (FLASH) and XFEL in Hamburg, the Linac Coherent Light Source (LCLS) at the SLAC National Accelerator Laboratory, the SPring-8 Compact SASE Source (SCSS), the SwissFEL at the Paul Scherrer Institute (Switzerland), and SACLA at the RIKEN Harima Institute in Japan. The characteristics of these sources are extraordinary, with peak brilliances more than a billion times brighter than synchrotrons and pulse-lengths down to less than a trillionth of a second (see Table 1), and are opening up entirely new branches of X-ray science.

A prime example is serial femtosecond diffraction (SFX). In SFX experiments nano-crystals are streamed through the X-ray pulses in a fine jet of liquid protected by a jacket of gas (Weierstall et al., 2012). Proof-of-concept experiments demonstrated that the pulse-length is short enough for diffraction patterns to be recorded before radiation damage can vaporize biological crystals (Chapman et al., 2007). Data sets of surprising quality can be compiled from thousands of diffraction shots taken from randomly oriented crystals that intersect the X-rays. A small proportion of the images can be indexed using conventional single crystal software, but scaling to generate complete 3D data sets is still challenging, and new methods such as Monte Carlo integration are being developed (Kirian et al., 2010; White et al., 2013; Qu, Zhou and Dong, 2014). In a ground-breaking experiment carried out at the LCLS in 2011, the structure of one of the largest membrane protein complexes, Photosystem-I, was solved by molecular replacement from an SFX experiment carried out on crystals of $200 \mathrm{~nm}$ to $2 \mu \mathrm{m}$ in size (Chapman et al., 2011). Independently, the structure of a photosynthetic reaction centre (Johansson et al., 2013) and combined crystallographic and spectroscopic studies on Photosystem-II, have provided profound insights into photosynthesis and demonstrated the potential of FEL experiments to probe complex reaction pathways (Kern et al., 2013). In another example the structure of Cathepsin-B, a potential target for therapies against African sleeping sickness, was

Table 1. Comparison of beam parameters between third generation and X-ray FEL sources

\begin{tabular}{lcccc}
\hline & $\begin{array}{c}\text { Third Generation } \\
\text { Sources }\end{array}$ & $\begin{array}{c}\text { LCLC } \\
\text { (Stanford) }\end{array}$ & $\begin{array}{c}\text { SACLA } \\
\text { (RIKEN) }\end{array}$ & $\begin{array}{c}\text { XFEL } \\
\text { (Hamburg) }\end{array}$ \\
\hline Min wavelength $(\mathrm{nm})$ & $100-0.1$ & 0.15 & 0.08 & 0.05 \\
\hline Emittance $(\mathrm{nm} . \mathrm{rad})$ & 2 to 10 & 0.05 & - & 0.03 \\
\hline Max electron energy (GeV) & $>8$ & 14.3 & 8 & 17.5 \\
\hline Typical Pulse length (fs) & $15000-30000$ & $300-100$ & 100 & 100 \\
\hline $\begin{array}{l}\text { Average brilliance } \\
\left.\text { (photons } / \mathrm{sec} / \mathrm{mm}^{2} / \mathrm{mrad}^{2} / 0.1 \% \mathrm{bw}\right)\end{array}$ & $10^{20}$ & $2.4 \cdot 10^{22}$ & $1.5 \cdot 10^{23}$ & $1.6 \cdot 10^{25}$ \\
\hline $\begin{array}{l}\text { Peak brilliance } \\
\left.\text { (photons } / \mathrm{sec} / \mathrm{mm}^{2} / \mathrm{mrad}^{2} / 0.1 \% \mathrm{bw}\right)\end{array}$ & $10^{23}$ & $2 \cdot 10^{33}$ & $1 \cdot 10^{33}$ & $5 \cdot 10^{33}$ \\
\hline
\end{tabular}


solved from crystals grown in vivo that were less than a micron thick (Redecke et al., 2013).

SFX experiments on membrane protein targets and cellular assemblies such as ribosomal subunits (Demirci et al., 2013) are now considered feasible. The crystal structure of the serotonin receptor, which belongs to a large group of membrane proteins called the $G$ protein-coupled receptors (GPCR), has been solved by an innovative SFX approach (Liu et al., 2013). To date, GPCR proteins have only been crystallised using meso techniques and this experiment involved the injection of Serotonin receptor crystals stabilized in meso phases into the X-ray path (Weierstall et al., 2014). The structure revealed the serotonin receptor bound to the migraine drug ergotamine and may well enable drugs modulating other biological responses linked to this receptor to be designed. More than $30 \%$ of current prescription drugs act on GPCR proteins marking this family is a major target for new drugs. Another key group of drug targets are membrane-bound kinases. SFX studies conducted on diacylglycerol kinase using a meso phase injector indicates that this approach can be adapted to a host of different membrane proteins (Caffrey et al., 2014).

\section{PERSPECTIVES}

The full potential of FEL technologies will only be realized in coming years but pioneering diffraction and imaging experiments are already being conceived. The combination of SFX and in meso crystallisation should open a pathway for medically important membrane complexes that have remained beyond the reach of structural techniques until now. The development of coherent diffraction and single molecule imaging techniques for biological samples at FEL has the power to transform structural biology. Time-resolved structural and spectroscopic studies will eventually allow biological mechanisms to be dissected unraveling the dynamic processes that drive nature. The FEL detector and injector technologies will improve to keep pace with novel experimental approaches as they have done at third generation sources. The larger FEL installations will quickly mature into stream-lined user facilities to service frontier X-ray science.

However, due to their formidable productivity and planned machine up-grades to significantly reduce emittance, third generation synchrotrons will remain the work-horses of X-ray science for the foreseeable future. Many of the latest storage rings have been designed with extended straight sections which can accommodate long FEL undulators. Synchrotron beamlines will close the gap in techniques such as serial crystallography and will implement approaches that can be integrated into their already well established pipe-lines. PX beamlines in general are moving towards more sophisticated sample delivery systems and greater flexibility in the design of diffraction experiments. Microfluidic technologies will have a major impact, both as static formats, such as high sample density chips, and continuous-flow injector systems. Sample characterisation using grid, helical and line scans will become increasingly sophisticated and will be tailored to the size and morphology of each sample. Hardware and control systems will support the synchronization of complex sample trajectories with fast detectors, enabling 2D and 3D data collection strategies. Advanced experimental work-flows will enable segments of data collected in different geometries, or from different positions, to be combined to generate the best complete data possible. Software to rank and scale together many independent partial data collections is being developed at several sites (Foadi et al., 2013) and will improve with increasingly refined statistical data models. PX operation modes will be flexible and more integrated with down-stream crystallization platforms, which should soon be able to transfer pre-determined sample coordinates to the beamline for analysis.

Perhaps the most impressive aspect in the development of light sources, which are after all large institutions, is the fast-pace of change. The fourth generation sources are still in their infancy but the possibilities of fifth generation sources based on energy-recovery Linacs, or micro-fabricated undulators (Harrison et al., 2012) and Laser Plasma WakeField Accelerators (Couprie et al., 2013), are already being pursued. Light sources naturally promote the formation of networks across disciplines and borders, and in the age of "big data" are very much symbols of modern globalized science. It is genuinely hard not to feel that light sources have come of age in the twenty-first century.

\section{ACKNOWLEDGEMENTS}

I would like to thank Martin Savko, Jordi Juanhuix, Andrew McCarthy \& José Miguel Mancheño for critically reading and improving this article. I am also grateful to Andrew Thompson, William Shepard, Matthieu Réfrégiers and the Proxima team at Soleil for their input and many interesting discussions. 
${ }^{\S}$ Emittance is a term which describes the average spread in position (beam size) and momentum (divergence) of particles in a beam, and is intimately linked to brilliance. Put simply, the lower the emittance the brighter the source.

${ }^{*}$ In vacuum undulators at $10 \mathrm{KeV}$ with minimum gap.

\section{REFERENCES}

Aishima J., Owen R. L., Axford D., Shepherd E., Winter G., Levik K., Gibbons, P., Ashton, A. y Evans, G. (2009). Highspeed crystal detection and characterization using a fast-readout detector. Acta Crystallographica, D66, pp. 1032-1035. http://dx.doi.org/10.1107/ S0907444910028192

Arndt, U. W. and Wonacott, A. J. (eds.) (1977). The Rotation Method in Crystallography. Amsterdam: North-Holland.

Axford D., Owen, R. L., Aishima, J., Foadi, J., Morgan, A. W., Robinson, J. I., Nettleship, J., Owens, R. J., Moraes, I., Fry, E. E., Grimes, J. M., Harlos, K., Kotecha, A., Ren, J., Sutton, G., Walter, T. S., Stuart, D. I. and Evans, G. (2012). In situ macromolecular crystallography using microbeams. Acta Crystallographica, D68, pp. 592-600. http://dx.doi.org/10.1107/ S0907444912006749

Bingel-Erlenmeyer, R., Olieric, V., Grimshaw, J. P. A., Gabadinho, J., Wang, X., Ebner, S. G., Isenegger, A., Schneider, R., Schneider, J., Glettig, W., Pradervand, C., Panepucci, E. H., Tomizaki, T., Wang, M. and Schulze-Briese, C. (2011). SLS crystallization platform at beamline X06DA - a fully automated pipeline enabling in situ X-ray diffraction screening. Crystal Growth \& Design, 11, 4, pp. 916-923. http://dx.doi.org/10.1021/cg101375j

Blewett, J. W. (1946). Radiation losses in the induction electron accelerator. Physical Review, 69, pp. 87-95. http:// dx.doi.org/10.1103/PhysRev.69.87

Bonifacio, R., Pellegrini, C. and Narducci, L. (1984). Collective instabilities and high-gain regime in a free electron laser. Optics Communication, 50, pp. 373378. http://dx.doi.org/10.1016/00304018(84)90105-6

Bosco, P., Colson, W. B. and Freeman, R. A. (1983). Quantum/classical mode evolution in the free-electron laser oscillators. IEEE Journal of Quantum Electronics, QE-19, pp. 272-281. http://dx.doi. org/10.1109/JQE.1983.1071871
Bourenkova, G. P. and Popov, A. N. (2010). Optimization of data collection taking radiation damage into account. Acta Crystallographica, D66, pp. 409-419. http://dx.doi.org/10.1107/ S0907444909054961

Bowler, M. W., Guijarro, M., Petitdemange, S., Baker, I., Svensson, O., Burghammer, M., Mueller-Dieckmann, C., Gordon, E. J., Flot, D., McSweeny, S. M. and Leonard, G. A. (2010). Diffraction cartography: applying microbeams to macromolecular crystallography sample evaluation and data collection. Acta Crystallographica, D66, pp. 855-864. http://dx.doi. org/10.1107/S0907444910019591

Brau, Ch. A. (2004). Modern Problems in Classical Electrodynamics. Oxford: Oxford University Press.

Broennimann, C., Eikenberry, E. F., Henrich, B., Horisberger, R., Huelsen, G., Pohl, E., Schmitt, B., Schulze-Briese, C. Suzuki, M., Tomizaki, T., Toyokawa, H. and Wagner, A. (2006). The Pilatus $1 \mathrm{M}$ detector. Journal of Synchrotron Radiation, 13, pp. 120-130. http://dx.doi. org/10.1107/S0909049505038665

Caffrey, M., Li, D., Howe, N. and Shah, S. T. A. (2014). 'Hit and run' serial femtosecond crystallography of a membrane kinase in the lipid cubic phase. Philosophical Transactions of the Royal Society $B, 369,20130621$. http://dx.doi. org/10.1098/rstb.2013.0621

Chapman, H. N., Hau-Riege, S. P., Bogan, M. J., Bajt, S., Barty, A., Boutet, S., Marchesini, S., Frank, M., Woods, B. W., Benner, W. H., London, R. A., Rohner, U., Szöke, A., Spiller, E., Möller, T., Bostedt, C., Shapiro, D. A., Kuhlman, M., Treusch, R., Plönjes, E., Burmeister, F., Begh, M., Caleman, C., Huldt, G., Seibert, M. M. and Hajdu, J. (2007). Femtosecond time-delay $\mathrm{X}$-ray holography. Nature, 448, pp. 676-679. http://dx.doi. org/10.1038/nature06049

Chapman, H. N., Fromme, P., Barty, A., White, T. A., Kirian, R. A., Aquila, A., Hunter, M.
S., Schulz, J., DePonte, D. P., Weierstall, U., Doak, R. B., Maia, F. R. N. C., Martin, A. V., Schlichting, I., Nicola Coppola, L. L., Shoeman, R. L., Epp, S. W., Hartmann, R., Rolles, D., Rudenko, A., Fouca, L., Kimmel, N., Weidenspointner, G., Holl, P. (2011). Femtosecond X-ray protein nanocrystallography. Nature, 470, pp. 73-77 http:// dx.doi.org/10.1038/nature09750

Chasman, R. and Green, G. K. (1975). Preliminary design of a dedicated synchrotron radiation facility. IEEE Transactions on Nuclear Science, 22, pp. 1765-1767. http://dx.doi.org/10.1109/ TNS.1975.4327987

Chavas, L. M. G., Matsugaki, N., Yamada, Y., Hiraki, M., Igarashi, N., Suzuki, M. and Wakatsuki, S. (2012). Beamline AR-NW12A: high-throughput beamline for macromolecular crystallography at the Photon Factory. Journal of Synchrotron Radiation, 19, pp. 450-454. http://dx.doi.org/10.1107/ s0909049512009727

Cherezov, V., Hanson, M. A., Mark T. Griffith, M. T., Hilgart, M. C., Sanishvili, R., Nagarajan, V., Stepanov. S., Fischetti, R. F., Kuhn, P. and Stevens, R. C. (2009). Rastering strategy for screening and centering of microcrystals samples of human membrane proteins with a sub- $10 \mu \mathrm{m}$ size X-ray. Journal of the Royal Society Interface, 6, pp. S587-S597. doi: 10.1098/ rsif.2009.0142.focus. http://dx.doi. org/10.1098/rsif.2009.0142.focus

Cipriani, F., Rower, M., Landret, C., Zander, U., Felisaz, F. and Marquez, J. A. (2012). CrystalDirect: a new method for automated crystal harvesting based on laser-induced photoablation of thin films. Acta Crystallographica, D68, pp. 1393-1399. http://dx.doi.org/10.1107/ S0907444912031459

Couprie, M. E., Benabderrahmane, C., Betinelli, P., Bouvet, F., Buteau, A., Cassinari, L., Daillant, J., Denard, J. C., Eymard, P., Gagey, B., Herbeaux, C., Labat, M., Lagarde, B., Lestrade, A., Loulergue, 
A., Marchand, P. Marlats, J. L., Miron, C., Morin, P., Nadij, A., Polack, F., Pruvost, J. B., Ribeiro, F., Ricaud, J. P., Roy, P., Tanikawa, T., Roux, R., Bielawski, S., Evain, C., Szwaj, C., Lambert, G., Lifschitz, A., Malka, V., Lehe, R., Rousse, A., Ta Phuoc, K., Taury, C., Devanz, G., Luong, M., Carré, B., LeBec, G., Farvacque, L.Dubois, A. and Lüning, J. (2013). The LUNEX5 project in France. Journal of Physics: Conference Series, 425, 072001. http://dx.doi. org/10.1088/1742-6596/425/7/072001

Dattoli, G., Gallardo, J. C., Renieri, A., Richetta, M. and Torre, A. (1985). Quantum coherence properties of the FEL. Nuclear Instruments and Methods in Physics Research A, 237, pp. 93-99. http://dx.doi. org/10.1016/0168-9002(85)90335-3

Dauter, Z. (1999). Data collection strategies. Acta Crystallographica, D55, pp. 1703-1717. http://dx.doi.org/10.1107/ S0907444999008367

Dauter, Z., Dauter, M. and Dobson, E. (2002). Jolly SAD. Acta Crystallographica, D58, pp. 494-506. http://dx.doi. org/10.1107/S090744490200118X

Dauter, Z. (2005). Efficient use of synchrotron radiation for macromolecular diffraction data collection. Progress in Biophysics and Molecular Biology, 89, pp. 153-172. http://dx.doi.org/10.1016/j. pbiomolbio.2004.09.004

Dean, A. J., Clark, D. J., Stephen, J. B., McBride, V. A., Bassani, L., Bazzano, A., Bird, A. J., Hill, A. B., Shaw, S. E. and Ubertini, P. (2008). Polarized gammaray emission from the Crab. Science, 321, pp. 1183-1185. http://dx.doi. org/10.1126/science.1149056

Degen, D., Feng, Y., Zhang, Y., Ebright, K. Y., Ebright, Y. W., Gigliotti, M., VahedianMovahed, H., Mandal, S., Talaue, M., Connell, N., Arnold, E., Fenical, W. and Ebright, R. H. (2014). Transcription inhibition by the depsipeptide antibiotic salinamide A. elife, 3, e02451. http:// dx.doi.org/10.7554/eLife.02451

Delagenière, S., Brenchereau, P., Launer, L., Ashton, A. W., Leal, R., Veyrier, S., Gabadinho, J., Gordon, E. J., Jones, S. D., Levik, K. E., McSweeney, S. M., Monaco, S., Nanao, M., Spruce, D., Svensson, O. Walsh, M. A. and Leonard, G. A. (2011). ISPyB: an information management system for synchrotron macromolecular crystallography. Bioinformatics, 27, pp. 3186-3192. http://dx.doi.org/10.1093/ bioinformatics/btr535
Demirci, H., Sierra, R. G., Laksmono, H., Shoeman, R. L., Botha, S., Barends, T. R. M., Nass, K., Schlichting, I., Doak, R. B., Gati, C., Williams, G. J., Boutet, S., Messerschmidt, M., Jogl, G. Dahlberg, A. E., Gregory, S. T. and Bogan, M. J. (2013). Serial femtosecond X-ray diffraction of $30 \mathrm{~S}$ ribosomal subunit microcrystals in liquid suspension at ambient temperature using $\mathrm{X}$-ray free-electronlaser. Acta Crystallographica, F69, pp. 1066-1069. http://dx.doi.org/10.1107/ S174430911302099X

Dhouib, K., Malek, C-K., Pfleging, W., Gauthier-Manuel, B., Duffait, R., G. Thuillier, G., Ferrigno, R., Jacquamet, L., Ohana, J., Ferrer, J. L., Théobald-Dietrich, A., Giegé, R., Lorber, B. and Sauter, C. (2009). Microfluidic chips for the crystallization of biomacromolecules by counterdiffusion and on-chip crystal X-ray analysis. Lab on a Chip, 9, pp. 1412-1421. http://dx.doi.org/10.1039/ b819362b

Elder, F. R., Gurewitsch, A. M., Langmuir, R. V. and Pollock, H. C. (1947). Radiation from electrons in a synchrotron. Physical Review, 71, pp. 829-830. http:// dx.doi.org/10.1103/PhysRev.71.829.5

Elder, F. R., Langmuir, R. V. and Pollock, H. C. (1948). Radiation from electrons accelerated in a synchrotron. Physical Review, 74, pp. 52-58. http://dx.doi. org/10.1103/PhysRev.74.52

Elias, L. R., Fairbank, W. M., Madey, J. M. J., Schwettman, H. A. and Smith, T. I. (1976). Observation of Stimulated Emission of Radiation by Relativistic Electrons in a Spatially Periodic Transverse Magnetic Field. Physical Review Letters, 36, pp. 717-720. http://dx.doi. org/10.1103/PhysRevLett.36.717

Evans, G., Axford, D., Waterman, D. and Owen R. L. (2011). Macromolecular microcrystallography. Crystallography Reviews, 17, pp. 105-142. http://dx.doi.or g/10.1080/0889311X.2010.527964

Foadi, J., Aller, P., Alguel, Y., Cameron, A., Axford, D., Owen, R., Armour, W., Waterman, D. G., Iwata, S. and Evans, G. (2013). Clustering procedures for the optimal selection of data sets from multiple crystals in macromolecular crystallography. Acta Crystallographica, D69, pp. 1617-1632. http://dx.doi. org/10.1107/S0907444913012274

Fodje, M., Janzen, K., Berg, R., Black, G., Labiuk, S., Gorin, J. and Grochulski, P. (2012). MxDC and MxLIVE: software for data acquisition, information management and remote access to macromolecular crystallography beamlines. Journal of Synchrotron Radiation, 19, pp. 274-280. http://dx.doi.org/10.1107/ S0909049511056305

Gati, C., Bourenkov, G., Klinge, M., Rehders, D., Stellato, F., Oberthür, D., Yefanov, O., Sommer, B. P., Mogk, S., Duszenko, M., Betzel, C., Schneider, T. R., Chapman, H. N. and Redecke, L. (2014). Serial crystallography on in vivo grown crystals using synchrtotron radiation. IUCrJ, 1-2, pp. 87-94. http://dx.doi.org/10.1107/ S2052252513033939

Harrison, J., Joshi, A., Lake, J., Candler, R. and Musumeci, P. (2012). Surface-micromachined magnetic undulator with period length between $10 \mu \mathrm{m}$ and 1 $\mathrm{mm}$ for advanced light sources. Physical Review Special Topics - Accelerators and Beams, 15, 070703. http://dx.doi. org/10.1103/PhysRevSTAB.15.070703

Hendrickson, W. A. and Ogata, C. M. (1997). Phase determination from multiwavelength anomalous diffraction measurements. Methods in Enzymology, 276, pp. 494-523. http://dx.doi. org/10.1016/S0076-6879(97)76074-9

Incardona, M.-F., Bourenkov, G. P., Levik, K., Pieritz, R. A., Popov, A. N. and Svensson. O. (2009). EDNA: a framework for plugin-based applications applied to X-ray experiment online data analysis. Journal of Synchrotron Radiation, 16, pp. 872-879. http://dx.doi.org/10.1107/ S0909049509036681

Iwanenko, D. and Pomeranchuk, I. (1944). On the maximal energy attainable in a bebatron. Physical Review, 65, p. 343. http://dx.doi.org/10.1103/PhysRev.65.343

Jacquamet, L., Ohana, J., Joly, J., Borel, F., Pirocchi, M., Charrault, P., Bertoni, A., Israel-Gouy, P., Carpentier, P., Kozielski, F., Blot, D. and Ferrer, J. L. (2004). Automated analysis of vapor diffusion crystallization drops with an X-ray beam. Structure, 12, pp. 1219-1225. http:// dx.doi.org/10.1016/j.str.2004.04.019

Johansson, L. C., Arnlund, D., Katona, G., White, T. A., Barty, A., DePonte, D. P., Shoeman, R. L., Wickstrand, C., Sharma, A., Williams, G. J., Aquila, A., Bogan, M. J., Caleman, C., Davidsson, J. Doak, R. B., Frank, M., Fromme, R., Galli, L., Grotjohann, I. and Hunter, M. S. (2013). Structure of a photosynthetic reaction centre determined by serial femtosecond crys- 
tallography. Nature Commununications, 4, 2911. http://dx.doi.org/10.1038/ ncomms3911

Kern, J., Alonso-Mori, R., Tran, R., Hattne, J., Gildea, R. J., Echols, N., Glöckner, C., Hellmich, J., Laksmono, H., Sierra, R. G., Lassalle-Kaiser, B., Koroidov, S., Lampe, A., Han, G., Gul, S., DiFiore, D., Milathianaki, D., Fry, A. R., Miahnarhri, A., Schafer, D. W., Messerschmidt, M., Seibert, M. M., Koglin, J. E., Sokaras, D., Weng T.-C., Sellberg, J., Latimer, M. J., Grosse-Kunstleve, R. W., Zwart, P. H., White, W. E., Glatzel, P., Adams, P. D., Bogan, M. J., Williams, G. J., Boutet, S., Messinger, J., Zouni, A., Sauter, N., Yachandra, V. K., Bergman, U. and Yano, J. (2013). Simultaneous femtosencond X-ray spectroscopy and diffraction of photosystem II at room temperature. Science, 340, pp. 491-495. http://dx.doi. org/10.1126/science.1234273

Khatter, H., Myasnikov, A. G., Mastio, L., Billas, I. M. L., Birck, C., Stella, S. and Klaholz, B. P. (2014). Purification, characterization and crystallization of the human $80 \mathrm{~S}$ ribosome. Nucleic Acids Research, 42, e49. http://dx.doi. org/10.1093/nar/gkt1404

Khounsary, A. M., Freund, A. K., Ishikawa, T., Srajer, G. and Lang, J. C. (eds.) (1999). $X$-ray optics design, performance, and applications. Proceedings SPIE 3773. Bellingham, WA.

Kim, K.-J. (1986). Three-dimensional analysis of coherent amplification and self-amplified spontaneous emission in Free-electron lasers. Physical Review Letters, 57, pp. 1871-1874. http://dx.doi.org/10.1103/PhysRevLett.57.1871

Kirian, R. A., Wang, X., Weierstall, U., Schmidt, K. E., Spence, J. C., Hunter, M., Fromme, P., White, T., Chapman, H. N. and Holton, J. (2010). Femtosecond protein nanocrystallography - data analysis methods. Journal of Optics Express, 18, pp. 5713-5723. http://dx.doi. org/10.1364/OE.18.005713

Krojer, T., Pike, A. C. W. and von Delft, F. (2013). Squeezing the most from every crystal: the fine details of data collection. Acta Crystallographica, D69, pp. 1303-1313. http://dx.doi.org/10.1107/ s0907444913013280

Landau, E.M., and Rosenbusch, J.P. (1996). Lipidic cubic phases: a novel concept for the crystallization of membrane pro- teins. Proceedings of National Academy of Sciences of the USA, 93, pp. 1453214535. http://dx.doi.org/10.1073/ pnas.93.25.14532

Larmor, J. (1897). A dynamical theory of the electric and luminiferous medium. Part III. Relations with material media. Philosophical Transactions of the Royal Society $A, 190$, pp. 205-493. http://dx.doi. org/10.1098/rsta.1897.0020

Lee, M. J. Y., Faucher, F. and Jia, Z. (2014). Growth of diffraction-quality protein crystals using a harvestable microfluidic device. Crystal Growth \& Design, 14, pp. 3179-3181. http://dx.doi.org/10.1021/ cg500450b

Liénard, A. (1898). Champ électrique et magnétique produit par une charge électrique concentrée en un point et animée d'un mouvement quelconque. L'Eclairage électrique, 16, p. 5.

Liu, W., Wacker, D., Gati, C., Han, G. W., James, D., Wang, D., Nelson, G., Weierstall, U., Katritch, V., Barty, A., Zatsepin, N. A., Li, D., Messerschmidt, M., Boutet, S., Williams, G. J., Koglin, J. E., Seibert, M. M., Wang, C., Shah, S. T. A., Basu, S., Fromme, R., Kupitz, C., Rendek, K. N., Grotjohann, I., Fromme, P. , Kirian, R. A., Beyerlein, K. R., White, T. A., Chapman, H. N., Caffrey, M., Spence, J. C. H., Stevens, R. C. and Cherezov, V. (2013). Serial femtosecond crystallography of G-coupled receptors. Science, 342, pp. 1522-1524. http://dx.doi.org/10.1126/ science. 1244142

Madey, J. M. J. (1971). Stimulated emission of Bremsstrahlung in a periodic magnetic field. Journal of Applied Physics, 42, pp. 1906-1913. http://dx.doi. org/10.1063/1.1660466

Minor W., Cymborowski, M., Otwinowski, Z. and Chruszcz, M. (2006). HKL-3000: the integration of data reduction and structure solution - from diffraction images to an initial model in minutes. Acta Crystallographica, D62, pp. 859-866. http://dx.doi.org/10.1107/ S0907444906019949

Monaco, S., Gordon, E., Bowler, M. W., Delagenière, S., Guijarro, M., Spruce, D., Svensson, O., McSweeney, S. M., McCarthy, A. A., Leonard, G. and Hanao, M. H. (2013). Automatic processing of macromolecular crystallography X-ray diffraction data at the ESRF. Journal of Applied Crystallography, 46, pp. 804-810. http://dx.doi. org/10.1107/S0021889813006195
Mueller, M., Wang, M. and Schulze-Briese, C. (2012). Optimal fine $\phi$-slicing for single-photon-counting pixel detectors. Acta Crystallographica, D68, pp. 42-56. http://dx.doi.org/10.1107/ S0907444911049833

Murphy, J. and Pellegrini, C. (1985). Generation of high-intensity coherent radiation in the soft-X-ray and vacumm-ultraviolet region. Journal of the Optical Society of America, B2, pp. 259-264. http:// dx.doi.org/10.1364/JOSAB.2.000259

O'Neill, G. K. (1956). Storage-ring synchrotron: device for high-energy physics research. Physical Review, 102, pp.14181419. http://dx.doi.org/10.1103/PhysRev.102.1418

Owen, R. L., Paterson, N., Axford, D., Aishima, J., Schulze-Briese, C., Ren, Fry, E. E., Stuart, D. I. and Evans, G. (2014). Exploiting fast detectors to enter a new dimension in room-temperature crystallography. Acta Crystallographica, D70, pp.1248-1256. http://dx.doi. org/10.1107/S1399004714005379

Pebay-Peyroula, E., Rummel, G., Rosenbusch, J. P. and Landau, E. M. (1997). $X$-ray structure of bacteriorhodopsin at 2.5 Angstroms from microcrystals grown in lipidic phases. Science, 277, pp. 1676-1681. http://dx.doi.org/10.1126/ science.277.5332.1676

Pellegrini, C. (1988). Progress toward a soft X-ray FEL. Nuclear Instruments and Methods in Physics Research A, 272, pp. 364-367. http://dx.doi. org/10.1016/0168-9002(88)90252-5

Perry, S. L., Roberts, G. W., Tice, J. D., Gennis, R. B. and Kenis, P. J. A. (2009). Microfluidic generation of lipidic mesophases for membrane protein crystallization. Crystal Growth \& Design, 9, pp. 2566-2569. http://dx.doi.org/10.1021/ cg900289d

Qu, K., Zhou, L. and Dong, Y.-H. (2014). An improved integration method in serial femtosecond crystallography. Acta Crystallographica, D70, pp. 1202-1211. http:// dx.doi.org/10.1107/S1399004714002004

Rajendran, C., Dworkowski, F. S. N., Wang, M. T. and Schulze-Briese, C. (2011). Radiation damage in room-temperature data acquisition with the PILATUS 6M pixel detector. Journal of Synchrotron Radiation, 18, pp. 318-328. http://dx.doi. org/10.1107/S090904951100968X

Redecke, L., Nass, K., DePonte, D. P., White, T. A., Rehders, D., Barty, A., Stellato, F., 
Liang, M., Barends, T. R., Boutet, S., Williams, G. J., Messerschmidt, M., Seibert, M. M., Aquila, A., Amlund, D., Bajt, S., Barth, T., Bogan, M. J., Caleman, C., Chao, T. C., Doak, R. B., Fleckenstein, H., Frank, M., Fromme, R., Gali, L. Grotjohann, I., Hunter, M. S., Johansson, L. C., Kassemeyer, S., Katona, G., Kirian, R. A., Koopman, R., Kupitz, C., Lomb, L., Martin, A. V., Mogk, S., Neutze, R., Shoeman, R. L., Steinbrener, J., Timneanu, N., Wang, D., Weierstall, U., Zatsepin, N. A., Spence, J. C., Fromme, P., Schlichting, I., Duszenko, M., Betzel, C. and Chapman, H. N. (2013). Natively inhibited Trypanosoma brucei cathepsin B structure determined by using an X-ray laser. Science, 339, pp. 227-230. http:// dx.doi.org/10.1126/science.1229663

Sawhney, K., Alcock, S., Sutter, J, Berujon, S., Wang, H. and Signorato, R. (2013). Characterization of a novel super-polished bimorph mirror. Journal of Physics: Conference Series, 425, pp. 052026. http://dx.doi.org/10.1088/17426596/425/5/052026

Schott, G. A. (1907). On the electron theory of matter and on radiation. Philosophical Magazine, 13, pp. 189-213. http://dx.doi. org/10.1080/14786440709463594

Schwinger, J. (1949). On the classical radiation of accelerated electrons. Physical Review, 75, pp. 1912-1925. http:// dx.doi.org/10.1103/PhysRev.75.1912

Soltis, S. M., Cohen, A. E., Deacon, A., Eriksson, T., González, A., McPhillips, S., Chui, H., Dunten, P., Hollenbeck, M., Mathews, I., Miller, M., Moorhead, P., Phizackerley, R. P., Smith, C., Song, J., van dem Bedem, H., Ellis, P., Kuhn, P., McPhillips, T., Sauter, N., Sharp, K., Tsyba, I. and Wolf, G. (2008). New paradigm for macromolecular crystallography experiments at SSRL: automated crystal screening and remote data col- lection. Acta Crystallographica, D64, p. 1210-1221. http://dx.doi.org/10.1107/ S0907444908030564

Stellato, F., Oberthür, D., Liang, M., Bean, R., Gati, C., Yefanov, O., Barty, A., Burckhardt, A., Fischer, P., Galli, L., Kirian, R. A., Meyer, J., Panneerselvam, S., Hong Yoon, C., Chervinskii, F., Speller, E., White, T. A., Betzel, C. Meents, A. and Chapman, H. N. (2014). Room-temperature macromolecular serial crystallography using synchrotron radiation. IUCrJ, 1, pp. 204-212. http://dx.doi. org/10.1107/S2052252514010070

Theveneau, P., Baker, R., Barrett, R., Beteva, A., Bowler, M. W., Carpentier, P., Caserotto, H., de Sanctis, D., Dobias, F., Flot, D., Guijarro, M., Guiraud, T., Lentini, M., Leonard, G. A., Mattenet, M., McArthy, A., McSweeney, S. M., Morawe, C., Nanao, M., Nurizzo, D., Ohlsson, S., Pernot, P., Popov, A. N., Round, A., Royant, A., Schmid, W., Snigirev, A., Surr, J. and Mueller-Dieckmann, C. (2013). The Upgrade Programme for the Structural Biology beam lines at the European Synchrotron Radiation Facility - High throughput sample evaluation and automation. Journal of Physics: Conference Series 425, 012001. http://dx.doi. org/10.1088/1742-6596/425/1/012001

Trastoy, B., Lomino, J. V., Pierce, B. G., Carter, L. G., Günther, S., Giddens, J. P., Snyder, G. A., Weiss, T. M., Weng, Z., Wang, L. X., Sundberg, E. J. (2014). Crystal structure of Streptococcus pyogenes Endos, an immunomodulatory endoglycosidase specific for human IgG antibodies. Proceedings of National Academy of Sciences of the USA, 111, pp. 6714-6719. http://dx.doi.org/10.1073/ pnas.1322908111

Warren, A. J., Armour, W., Axford, D., Basham, M., Connolley, T., Hall, D. R., Horrell, S., McAuley, K. E. and Mykhaylyk, A. (2013). Visualization of membrane protein crystals in lipid cubic phase using X-ray imaging. Acta Crystallographica, D69, pp. 1252-1259. http://dx.doi. org/10.1107/S0907444913011359

Weierstall, U., Spence, J. C. H. and Doak, R. B. (2012). Injector for scattering measurements on fully solvated biospecies. Review of Scientific Instruments, 83, 035108. http://dx.doi. org/10.1063/1.3693040

Weierstall, U., James, D., Wang, Ch., White, T. A., Wang, D., Liu, W., Spence, J. C. H., Doak, R. B., Nelson, G., Fromme, P., Fromme, R., Grotjohann, I., Kupitz, C., Zatsepin, N. A., Liu, H., Basu, S., Wacker, D., Won Han, G., Katrich, V., Boutet, S. (2014). Lipidic cubic phase injector facilitates membrane protein serial femtosecond crystallography. Nature Commununications, 5, p. 3309. http:// dx.doi.org/10.1038/ncomms4309

White, T. A., Barty, A., Stellato, F., Holton, J. M., Kirian, R. A., Zatsepin, N. A. and Chapman, H. N. (2013). Crystallographic data processing for free-electron laser sources. Acta Crystallographica, D69, pp. 1231-1240. http://dx.doi. org/10.1107/S0907444913013620

Winter. G. (2010). xia2: an expert system for macromolecular crystallography data reduction. Journal of Applied Crystallography, 43, pp.186-190. http://dx.doi. org/10.1107/S0021889809045701

Zeldin, O. B., Gerstel, M. and Garman, E. F. (2013). RADDOSE-3D: time- and space-resolved modelling of dose in macromolecular crystallography. Journal of Applied Crystallography, 46, pp. 1225-1230. http://dx.doi.org/10.1107/ S0021889813011461

Zwart, P. H., Grosse-Kunstleve, R. W. and Adams, P. D. (2005). Xtriage and Fest: automatic assessment of $X$-ray data and substructure structure factor estimation. CCP4 newsletter, 43. 